\title{
Modulatory Effect of Citrate Reduced Gold and Biosynthesized Silver Nanoparticles on $\alpha$-Amylase Activity
}

\author{
Kantrao Saware, ${ }^{1}$ Ravindra Mahadappa Aurade, ${ }^{2}$ \\ P. D. Kamala Jayanthi, ${ }^{2}$ and Venkataraman Abbaraju ${ }^{1,3}$ \\ ${ }^{1}$ Materials Chemistry Laboratory, Department of Materials Science, Gulbarga University, Gulbarga, Karnataka 585106, India \\ ${ }^{2}$ Indian Institute of Horticultural Research, Hessaraghatta Lake Post, Bengaluru, Karnataka 5600 89, India \\ ${ }^{3}$ Department of Chemistry, Gulbarga University, Gulbarga, Karnataka 585106, India \\ Correspondence should be addressed to Venkataraman Abbaraju; raman_chem@rediffmail.com
}

Received 28 July 2014; Accepted 5 October 2014

Academic Editor: Amir Kajbafvala

Copyright (C) 2015 Kantrao Saware et al. This is an open access article distributed under the Creative Commons Attribution License, which permits unrestricted use, distribution, and reproduction in any medium, provided the original work is properly cited.

\begin{abstract}
Amylase is one of the important digestive enzymes involved in hydrolysis of starch. In this paper, we describe a novel approach to study the interaction of amylase enzyme with gold nanoparticles (AuNPs) and silver nanoparticles (AgNPs) and checked its catalytic function. AuNPs are synthesized using citrate reduction method and AgNPs were synthesized using biological route employing Ficus benghalensis and Ficus religiosa leaf extract as a reducing and stabilizing agent to reduce silver nitrate to silver atoms. A modulatory effect of nanoparticles on amylase activity was observed. Gold nanoparticles are excellent biocompatible surfaces for the immobilization of enzymes. Immobilized amylase showed 1- to 2-fold increase of activity compared to free enzyme. The biocatalytic activity of amylase in the bioconjugate was marginally enhanced relative to the free enzyme in solution. The bioconjugate material also showed significantly enhanced $\mathrm{pH}$ and temperature stability. The results indicate that the present study paves way for the modulator degradation of starch by the enzyme with AuNPs and biogenic AgNPs, which is a promising application in the medical and food industry.
\end{abstract}

\section{Introduction}

Nanoparticles are defined as particulate dispersions with a size in the range of 10-100 $\mathrm{nm}$ [1]. The nanostructures have also a great potential in biotechnological processes taking into account that each may be used as carriers for enzymes during different biocatalytic transformations [2]. Different types of biomolecules such as proteins, enzymes, antibodies, and anticancer agents can be immobilized on these nanoparticles.

Interaction of metal nanoparticles with biomolecules has received much attention in the recent years for the development of diagnostics, for sensors, and for targeted drug delivery. Further, nanoparticles also have promising medical applications for wound healing, diagnostics, biosensing, and drug delivery [3-6]. Increased activity of glucose oxidase was noticed when immobilized onto AgNPs [7]. AgNPs, a potential nanocatalyst for the rapid degradation of starch hydrolysis by $\alpha$-amylase, were studied by researchers [8]. The functionlised AuNPs have been extensively used for the detection of various enzymes and also for measurement of their activity [9-11]. For example, chemical or electrostatic attachment of enzymes to functionlised AuNPs may alter the catalytic properties either by increasing or by decreasing the affinity for enzyme-substrate formation [12-14]; enhancing its stability $[12,13]$; enhancing the rate of product formation (although significant report in this regard is still lacking) [12, 13] or retention [15]; and even having some loss of activity of the enzyme [16]. Similarly, interaction with AuNPs has been found to enhance the stability of peptides [17]. Their unique property arises specifically from higher surface to volume ratio and increased percentage of atoms at the grain boundaries. They represent an important class of materials in the development of novel devices that can be used in various physical, biological, biomedical, and pharmaceutical applications [18-20]. Nanotechnology has a wide application in 
pest management as nanocapsules for herbicide delivery, vector/pest control, and nanosensors for pest detection [21]. Synthesized silver or gold nanoparticles also help to produce new insecticides and insect repellants.

AuNPs and biointeractions studies are now widely accepted as protein corona rapidly forms on AuNPs surfaces when introduced into a biological medium [22]. The adsorption of proteins to the surface of the AuNPs can significantly change the surface charge of the AuNPs, which has important consequences for nanoparticle fate and transport in biological systems. Therefore, the composition of the protein corona largely defines the biological identity of the nanoparticle. In addition, because of their extremely large surface area to volume ratios, a significant number of proteins can be adsorbed and "trapped" on AuNPs surfaces when they are introduced into biological entities [22-27]. Gold nanoparticles present an alternate and advantageous synthetic scaffold for targeting protein surfaces [28] and have been demonstrated to bind biomacromolecules, [29] facilitate DNA transfection [30], and reversibly inhibit enzymes [31]. The binding of albumin protein on the surfaces of silver and gold nanoparticles has been studied for surface adhesion by researchers to understand the effect on its structural changes $[32,33]$. Biointeraction studies with AgNPs and protein and its SPR effect, surface charge effect was studied for various applications in biological sciences by various researchers [34, 35].

Enzymes are biological catalysts that speed up reactions in the presence or absence of cofactors without any change in their activity. $\alpha$-Amylase is one of the chief digestive enzymes present in all living organisms and amylases in saliva/the pancreas of animals break down the long-chain polysaccharide starch into maltose and glucose. Amylases are the most important in food industry and medicinal applications.

So in this study, we used silver and gold nanoparticles for the interaction and catalytic action of $\alpha$-amylase. The present study aims to investigate enzyme-catalyzed starch hydrolysis in the presence of AuNPs and green AgNPs. This forms a basis for nanoparticle-bimolecular interaction that may be potentially applied in the medical and food industry. Thus, we report here the modulation of enzymatic activity in the presence of AuNPs and AgNPs. Absorbance, fluorescence spectroscopic measurements, and other chemical tests were done to establish that the enzymes were attached to the NPs.

\section{Materials and Methods}

2.1. Chemicals and Reagents. $\alpha$-Amylase (ex-porcine extrapure), soluble starch, $\mathrm{AgNO}_{3}, \mathrm{HAuCl}_{4}$, and ammonium molybdate purchased from Himedia, Bangalore, India, and all other chemicals used were of high purity and analytical grade. For all the experiments, ultrafiltered Milli-Q water (Millipore, USA) was used.

2.2. Synthesis of Gold Nanoparticles. Gold nanoparticles of $10-20 \mathrm{~nm}$ diameter were prepared by the citrate reduction route [36]. Briefly the method involves reducing $5 \times 10^{-4} \mathrm{M}$
$\mathrm{Au}^{+3}$ by $1.2 \times 10^{-3} \mathrm{M}$ citrate in water by refluxing for $30 \mathrm{~min}$. The cluster solution was red wine for gold [37].

2.3. Biosynthesis of Silver Nanoparticles. Biosynthesis of silver nanoparticles is according to our previous report [38]. The Ficus benghalensis (FB) and Ficus religiosa (FR) leaf extracts are used for synthesis of silver nanoparticles. Fresh, healthy, and green leaves from FR and FB plants were collected from the Gulbarga University campus, Gulbarga, India. In this experiment, $5 \mathrm{~mL}$ of leaf extract was added to $95 \mathrm{~mL}$ of a $10^{-3} \mathrm{M}$ aqueous $\mathrm{AgNO}_{3}$ (silver nitrate) solution and exposed for $3 \mathrm{~min}$ in microwave oven. Periodically aliquots of the reaction solution were removed and subjected to UV-Vis spectroscopy measurements for surface Plasmon resonance study of AgNPs synthesis. Controls containing leaf extract (without silver nitrate) as positive controls and pure silver nitrate solution (without leaf extract) as negative controls were also run simultaneously along with the experimental flask in three replicates.

2.4. UV-Visible Spectral Studies. The measurement of maximum absorbance peak of AuNPs and AgNPs was carried out using U-3010 spectrophotometer. UV-visible absorbance spectrum was measured between 200 and $800 \mathrm{~nm}$ in $1 \mathrm{~cm}$ quartz cuvette containing $2 \mathrm{~mL}$ of nanoparticle solution at room temperature. Interactions of silver and gold nanoparticles with amylase were measured spectrophotometrically. UV-visible absorbance spectrum was measured between 200 and $800 \mathrm{~nm}$ in $1 \mathrm{~cm}$ quartz cuvette containing protein $(50 \mu \mathrm{g} / \mathrm{mL})$ in $50 \mathrm{mM}$ Tris- $\mathrm{HCl}$ buffer, with $\mathrm{pH} 7.4$ at room temperature. Amylase in Tris- $\mathrm{HCl}$ buffer is titrated with increasing concentrations $(0,5,10,20,30$, and $50 \mu \mathrm{L})$ of silver and gold nanoparticles.

2.5. Tryptophan Fluorescence Emission Spectra. The interaction of binding of silver and gold nanoparticles to pure $\alpha$-amylase was determined by Trp fluorescence quenching titrations as described previously [39]. Briefly, amylase $(50 \mu \mathrm{g} / 2 \mathrm{~mL})$ was titrated in $50 \mathrm{mM}$ Tris- $\mathrm{HCl}$ buffer, with $\mathrm{pH}$ 7.4 with increasing concentrations of silver and gold nanoparticles $(0,5,10,20,30,40$, and $50 \mu \mathrm{L})$, respectively. However, quenching of Trp fluorescence emission of amylase was monitored at $335 \mathrm{~nm}$ following excitation at $280 \mathrm{~nm}$ (slit width for both, $5 \mathrm{~nm}$ ) using Varian spectrofluorometer.

2.6. Morphological Studies Using AFM for AgNPs and FESEM for AuNPs. Samples of silver nanoparticles were synthesized using leaf extracts of FB and FR. Atomic force microscopy (AFM) was prepared by solution casting onto silicon wafers to make thin films. These films were analysed in noncontact mode using a Pacific Nanotechnology Nano-R2 instrument with $\mathrm{SiN}$ probes at a scan rate of $0.5 \mathrm{~Hz}$ in the air. The morphology of the gold nanoparticles synthesized by citrate reduction method and AuNPs with amylase enzyme was examined using Field Emission Scanning Electron Microscopy (FESEM, FEI Nova nano 600, Netherlands), and for this the images were operated at $15 \mathrm{KV}$ on a $0^{\circ}$ tilt position. 
2.7. Immobilization of Amylase. Amylase-silver and gold nanoparticles bioconjugates were prepared according to [40]. Briefly, the AgNPs/AuNPs solution prepared was diluted by a factor of 3 with a glycine buffer $(75 \mathrm{mM}, \mathrm{pH} 8.0)$. Amylase $(\mathrm{mg} / \mathrm{mL})$ was added with stirring to a portion of the diluted solution containing the AgNPs/AuNPs $(50 \mathrm{~mL} ; 50 \mathrm{mM}$ glycine buffer, $\mathrm{pH}$ 8.0). The solution was equilibrated for $1 \mathrm{~h}$ before being centrifuged at $18,000 \mathrm{rpm}$ for $20 \mathrm{~min}$ to remove the uncoordinated amylase remaining in solution. The precipitate obtained was subjected to three repeated wash cycles involving rinsing with $50 \mathrm{mM}$ glycine buffer $(50 \mathrm{~mL})$ and centrifuging at $18.000 \mathrm{rpm}$ for $20 \mathrm{~min}$. Finally, the AgNPamylase and AuNPs-amylase bioconjugates were suspended in the $50 \mathrm{mM}$ glycine buffer, with $\mathrm{pH} 8(5 \mathrm{~mL})$ for further experiments.

2.8. Amylase Activity by DNS Method. The amylase activity was measured in presence of silver and gold nanoparticles as reported earlier [41]. Amylase activity was measured in presence of different concentrations of silver and gold nanoparticles by DNS method. We also assay the effect of nanoparticles on amylase activity with increasing concentrations of starch. Briefly, the activity was estimated by DNS method, enzymeAuNPs bionanoconjugates was added to various test tubes each containing $0,0.25,5,10,20,30,40$, and $50 \mathrm{mg} \mathrm{mL}^{-1}$ of starch solution. All of these test tubes were then incubated in a water bath at $37^{\circ} \mathrm{C}$ for $20 \mathrm{~min}$. The UV-Vis spectrum was recorded at 570 using a U-3010 spectrophotometer (Tokyo, Japan). The released sugar in the test sample was quantified and the enzyme activity was calculated (expressed in $\mu \mathrm{g} / \mathrm{mL} / \mathrm{min}$ ). We also assayed stabilities of the free and immobilized $\alpha$-amylase which was studied according to [42]. All the experiments were performed at least three times.

\section{Results and Discussion}

The present study reveals the modulatory effect of AuNPs and biosynthesized AgNPs on enzyme activity during the hydrolysis of starch. The solution turned pale yellow after $2 \mathrm{~min}$, and the colour change confirmed the presence of AgNPs. The organic moiety of soluble leaf extract is assumed to reduce silver nitrate, thus acting as both stabilizing and reducing agent [43]. The Plasmon peak observed at 435 and $440 \mathrm{~nm}$ confirmed the presence of AgNPs (Figures 1(a) and 1(b)). The absorbance peaks that occurred at around $400 \mathrm{~nm}$ are the characteristic SPR signature of AgNPs [44]. The HAucl reduced by citrate reduction showing red wine color after 10 min confirmed the formation of gold nanoparticles and the SPR peak is observed at $510 \mathrm{~nm}$ (Figure 2). The absorbance peak around $526 \mathrm{~nm}$ with the peak position remaining practically constant also indicates the production of gold nanoparticles [45]. We observed a faint pink coloration of the solution after several pulses of the experiment. In the solutions absorption spectra, the surface Plasmon peak (around $510-530 \mathrm{~nm}$ ) could be clearly distinguished which was consistent with the presence of small $3-30 \mathrm{~nm}$ particles in the colloid [46]. It was also noted that the resulting AuNPs and AgNPs nanoparticle solutions were found to be stable for more than a month without agglomeration of particles.

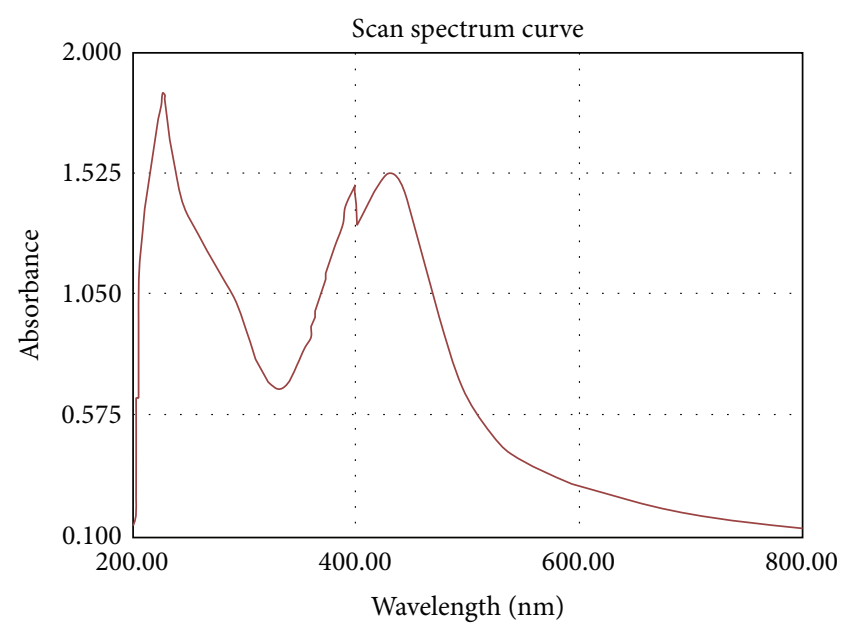

(a)

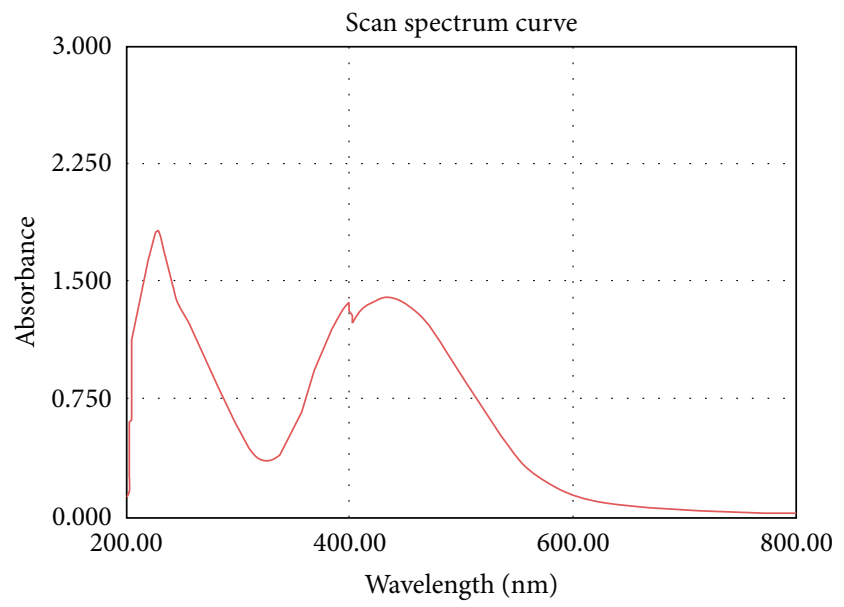

(b)

FIgURE 1: Absorbance spectra of silver nanoparticles. (a) Spectra of FR nanoparticles; (b) spectra of FB silver nanoparticles.

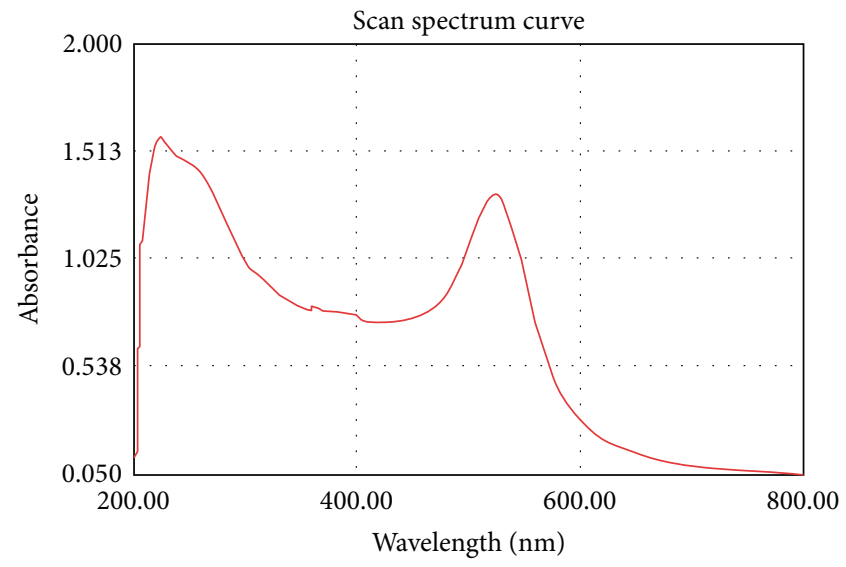

FIGURE 2: Absorbance spectra of gold nanoparticles.

Atomic force microscopy (AFM) was used to probe the sample's surface morphology and roughness. Figure 3 shows the typical three-dimensional (3D) height image of silver 


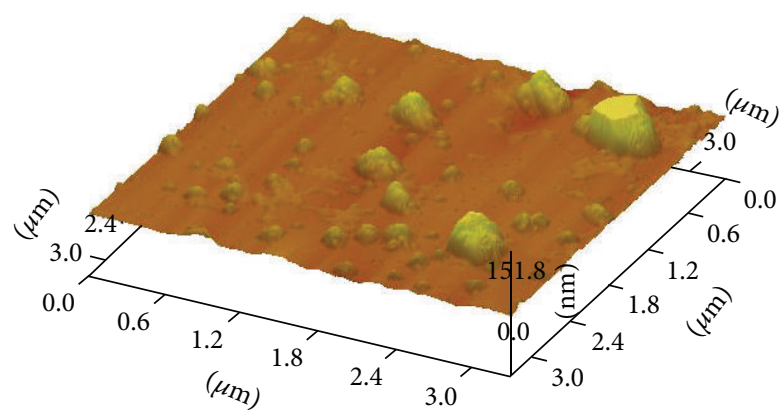

(a)

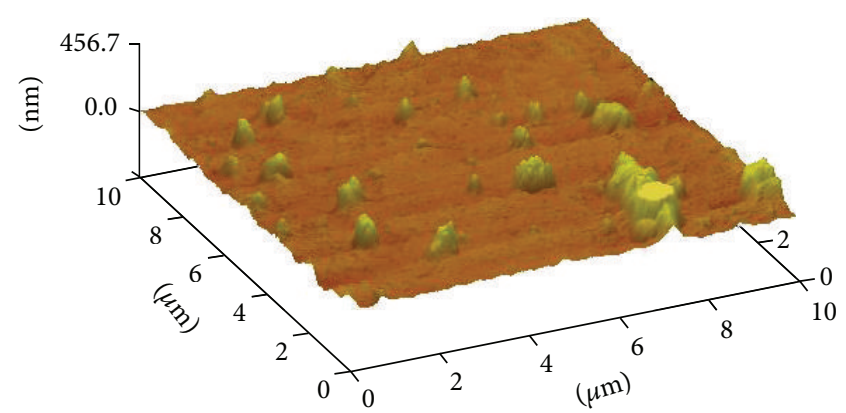

(b)

Figure 3: 3D image of AgNPs using atomic force microscopy. (a) AgNPs of Ficus benghalensis and (b) Ficus religiosa.

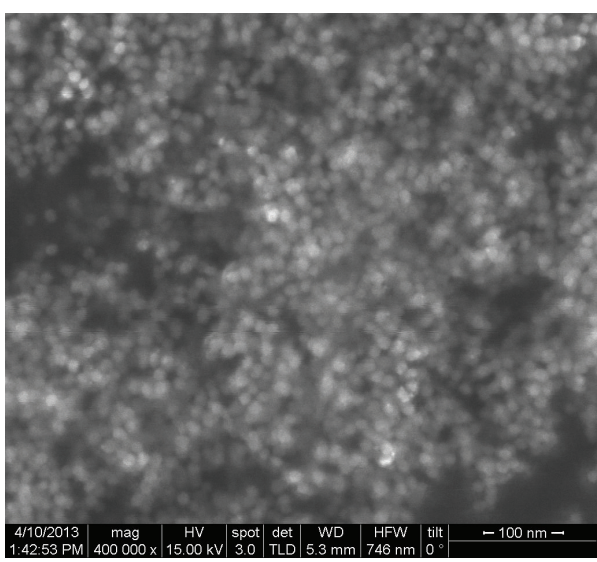

(a)

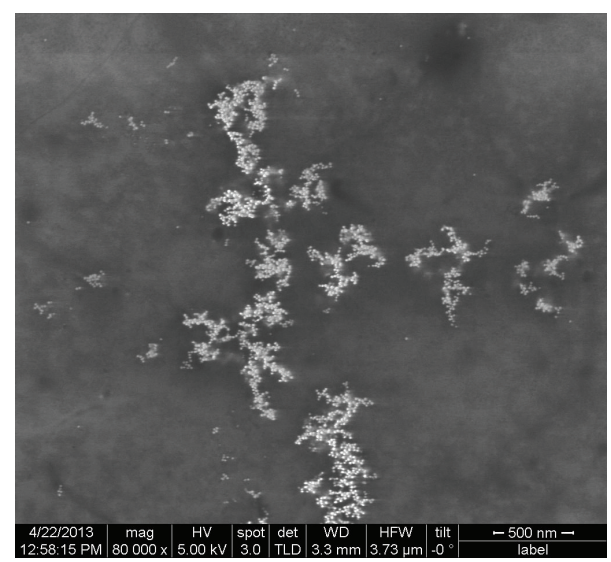

(b)

FIGURE 4: (a) FESEM image of citrate reduced gold nanoparticles $10-15 \mathrm{~nm}$. (b) Citrate reduced gold nanoparticles with $\alpha$-amylase enzyme.

nanoparticles with surface having spherical particles with grains sized between 20 and $75 \mathrm{~nm}$ in diameter with mean size of about $35 \mathrm{~nm}$. This magnification is attributed to the convolution of true particle size with that of the AFM tip (the size and shape of the features observed by AFM can be influenced by the effects of tip-sample convolution) and also to the preparation of samples for AFM. Wider scans covering a few micrometers yielded a root mean square (RMS) roughness of $10 \mathrm{~nm}$ with a maximum peak-to-valley distance of $65 \mathrm{~nm}$.

To understand the core-shell morphology of the synthesized AuNPs- and AuNPs-amylase bioconjugate FESEM technique was employed. Figure 4 shows the FESEM images of the AuNPs synthesized using citrate reduction method. On careful observation, each individual AuNP is seen as spherical in shape, whereas AuNPs and amylase bioconjugate showed a fine capping on each particle and the same may also be responsible for interparticle binding. It is observed from this image that the nanoparticles are isolated and are surrounded by a layer of organic matrix at some places which acts as capping. Almost all of the AuNPs are spherical in shape and are in the size range of $10-15 \mathrm{~nm}$ indicating monodispersity.

The UV-Vis absorbance spectra were recorded from the $\alpha$-amylase solution before (spectrum 1) and after (spectra 25) addition of AgNPs of FR (Figure 5(a)) and FB (Figure 5(b)) silver colloidal solution $(0,5,10,20,30$, and $50 \mu \mathrm{L})$. With the addition of silver nanoparticles, an increase was noticed in absorbance spectra. The blue shift of $\alpha$-amylase $(2-8 \mathrm{~nm})$ was seen for both FB and FR nanoparticles, respectively. The results indicate that these silver nanoparticles interacted with amylase and affect its folding changes toward native structure. Similarly gold nanoparticles also interacted with amylase and enhanced the absorbance spectra of amylase with the addition of increasing concentration of AuNPs (Figure 5(c)) and a slight conformational change of $\alpha$-amylase with interaction of AuNPs was observed.

Tryptophan fluorescence quenching measurement results showed that AgNPs and AuNPs interacted and bound with high affinity to amylase. The Trp emission spectra were decreased with addition of increasing concentrations of FB and FR nanoparticles (Figures 6(a) and 6(b)). The Trp fluorescence emission of amylase was quenched almost $30-60 \%$ by FR and FB AgNPs, respectively. However, there is no emission shift with addition of AgNPs.

Similarly, the Trp emission spectra were decreased with addition of increasing concentrations of AuNPs (Figure 6(c)). AuNPs interacted with high affinity with amylase and a small blue shift was observed. The results indicate that AuNPs interacted and bound with amylase with high affinity causing conformational changes of amylase. Earlier, Deka et al. [41] reported that gold nanoparticles interacted with $\alpha$-amylase. 


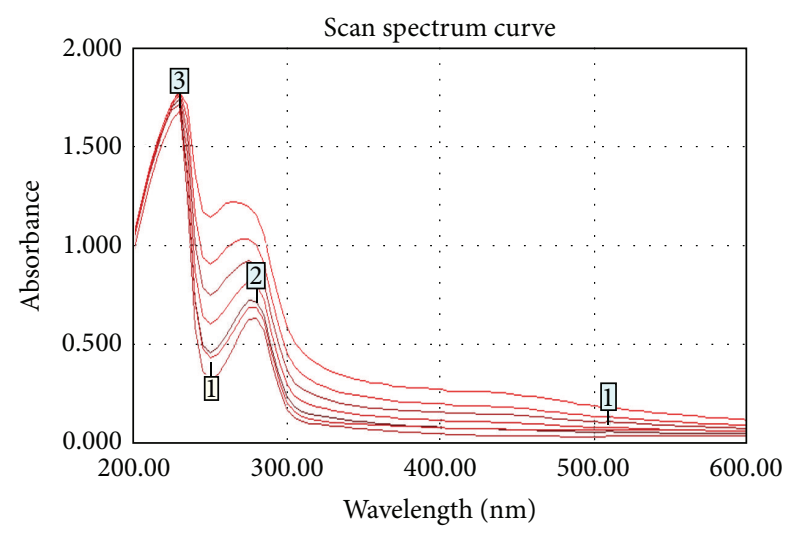

(a)

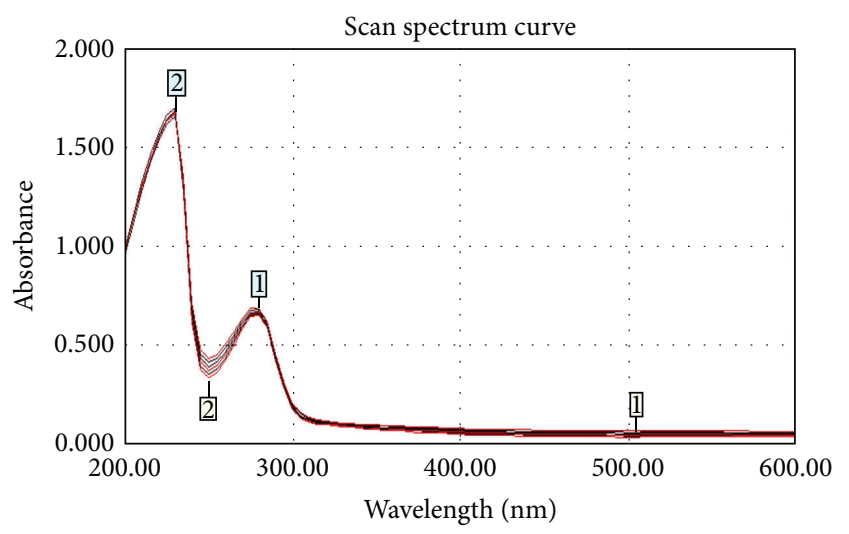

(b)

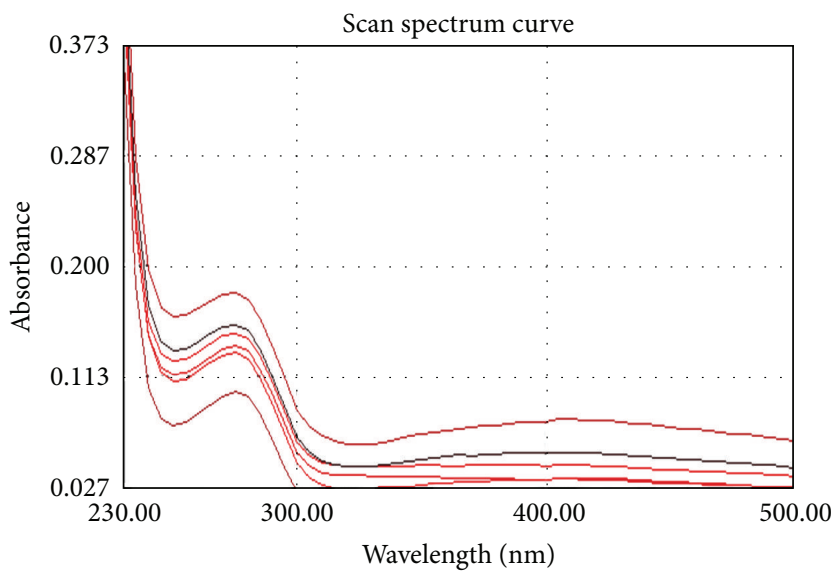

(c)

FIGURE 5: Measurement of absorbance spectrum of $\alpha$-amylase in presence of nanoparticles. Absorbance spectra of $\alpha$-amylase at pH 7.4. Absorbance spectra were increasing with addition of (a) FR silver nanoparticles; (b) FB silver nanoparticles (5, 10, 20, 30, 40, and 50 $\mu \mathrm{L}$ ), respectively; and (c) gold nanoparticles.

Ernest et al. reported that AgNPs enhance amylase activity [8]. We also observed that FR silver nanoparticles stimulate amylase activity at lower concentrations and inhibited it at higher concentration as shown in Figure 7. Similarly, FB nanoparticles also stimulated amylase activity at lower concentration and inhibited it at higher concentration. Silver nanoparticles demonstrated activator effect on the cholinesterase and monoamine oxidase activities, and these effects increased with increasing concentrations of the nanoparticles [47]. The enzyme was attached to the nanoparticle following the degradation of starch from the composite and not to the reducing sugars although the enzymatic activity was retained [48]. We also found that gold nanoparticles increased amylase activity up to 2 -fold. The rate of reaction was found to be increased in the presence of gold nanoparticles (Figure 7(b)). There is an increase of 2 -fold reducing sugar formation suggesting that the gold nanoparticles have a significant role as a nanocatalyst in rapidly degrading the complex polysaccharide starch to reducing sugars, while at higher concentrations of gold particles amylase activity was decreased. Deka et al. [41] also reported similar modulatory effect on amylase where the results have been explained based on a model that considered the presence of enzyme bound to NP and that available for enhanced catalysis, enzyme bound to NP but unavailable due to being buried inside the agglomerate and the free enzyme.

The immobilization of $\alpha$-amylase takes places on the surface of the FR and FB AgNPs or AuNPs. Immobilized amylase activity was increased by $60-90 \%$, (Figure $8(\mathrm{a})$ ) with FR and FB AgNPs, respectively, when compared to the free enzyme. AgNPs generally have the tendency to agglomerate faster in any biological medium and sediment at the bottom. To our surprise, no such agglomeration was seen during the reaction and thus we confirm that the AgNPs have the chances of being stabilized by the protein molecule through the thiol linkages, and thus the enzyme molecule is immobilized [48]. A well-known fact is that, upon a solid support, the efficiency of the enzyme is increased compared to its free form [49]. This may possibly act as a nanocatalyst in the hydrolysis of starch catalyzed by an amylase. Thus, the reaction rate is increased in the presence of AgNPs although the exact binding mechanism remains to be explored. Similarly, Figure 8(b) shows that immobilized amylase on gold nanoparticles activity was increased by $100 \%$ when compared 


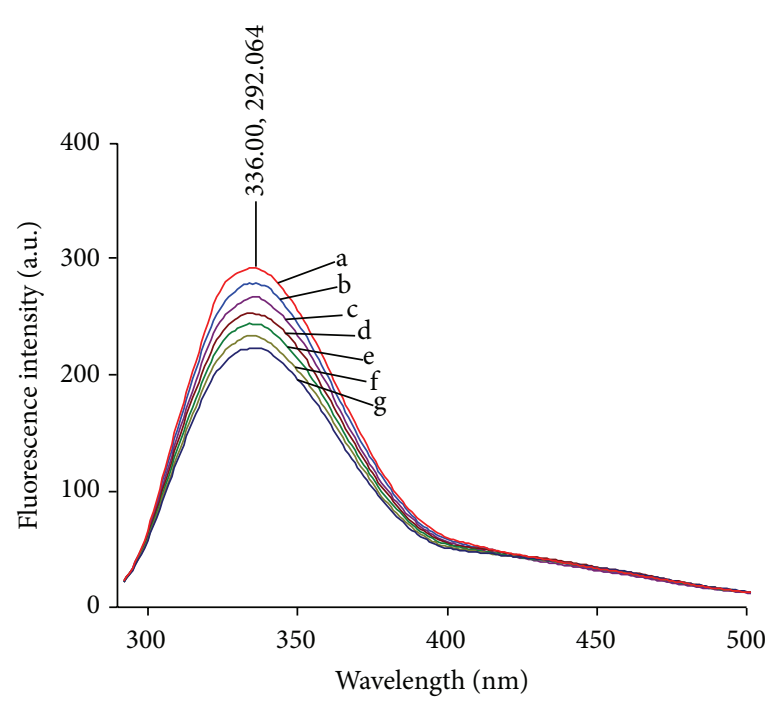

(a)

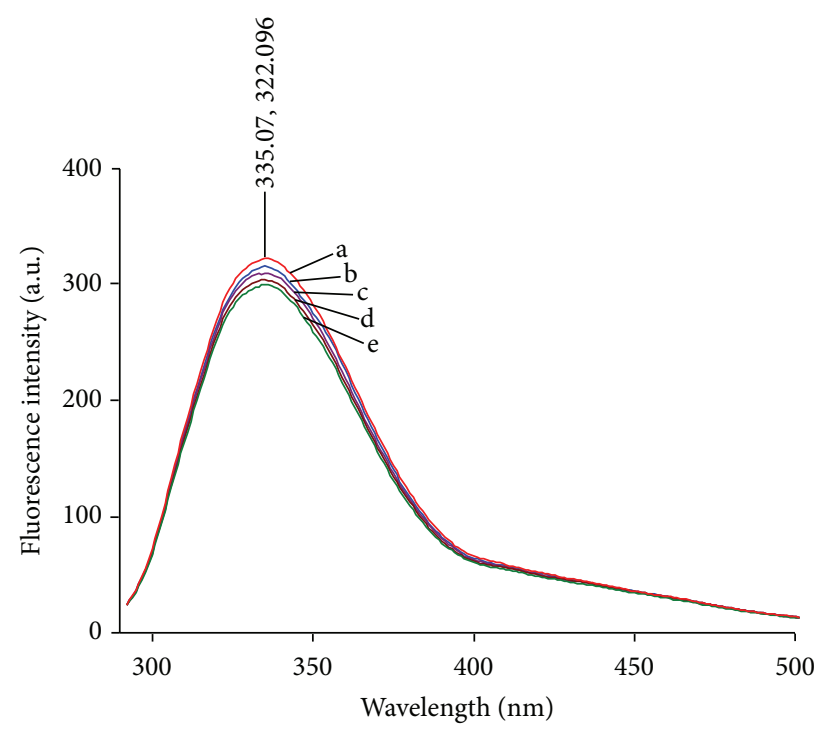

(b)

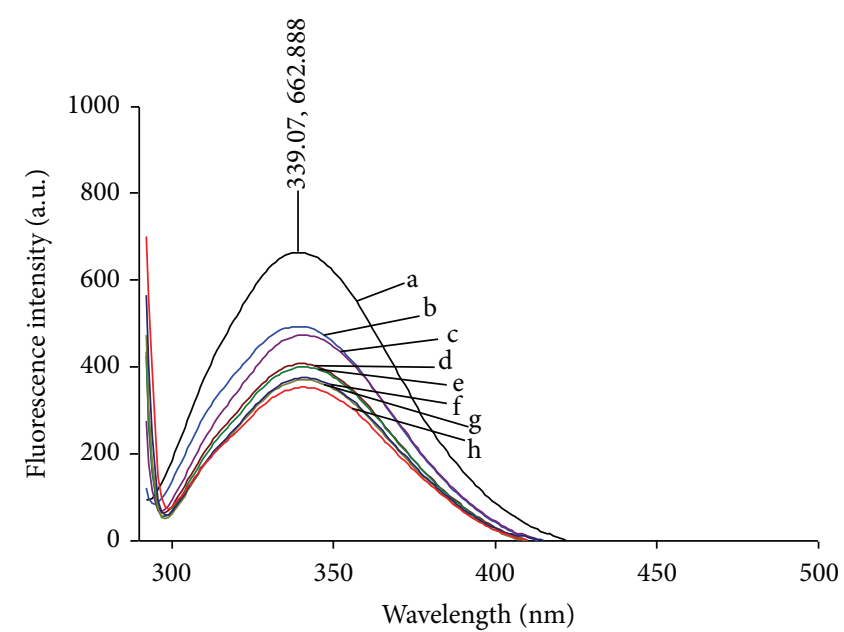

(c)

FIGURE 6: Tryptophan fluorescence quenching spectra of $\alpha$-amylase with nanoparticles. Line (a) corresponds to amylase alone; Line (b-g) with nanoparticles. (a) Amylase + FB AgNPs; (b) amylase + FR AgNPs; (c) amylase + gold nanoparticles. Decreasing of Trp fluorescence spectra with increasing $(5,10,15,20$, and $30 \mu \mathrm{L})$ concentration of silver and gold nanoparticles. Amylase titrated with increasing concentration of nanoparticles excitation at $280 \mathrm{~nm}$ followed emission at $335 \mathrm{~nm}$ (slit width for both $5 \mathrm{~nm}$ ).

with free enzymes. In our present study, biosynthesized AgNPs and citrate reduced AuNPs upon interaction with $\alpha$-amylase were capable of breaking down the starch complex with the attachment of the enzyme over its surface, thereby being immobilized and degrading starch much faster than when compared to free enzyme. Because the collision frequency between the soluble (free) enzyme, the substrate molecule and their steric orientations form the basis of the enzyme activity and the constraint is overcome by the immobilized enzyme with the support of a solid nanoparticle whereas it does not occur in the case of free starch. Therefore, the reaction velocity is high and the breakdown of starch to smaller molecules as monosaccharides and disaccharides is faster. Amylase activity was increased with increasing concentration of starch in presence of nanoparticles as shown in Figure 9. It indicates that nanoparticles enhance the basal amylase activity.

Pepsin immobilized on AuNPs surface was more stable when compared with the free enzyme [50]. Similarly we observed that AgNPs and AuNPs were increasing the stability of amylase activity. Free amylase and amylase mixed with AuNPs or AgNPs solutions were kept at room temperature for 5 days and the comparison of the activities was determined every 12 hours. The results showed a slight enzyme activity retained in all tests; this kind of stability increase is time dependent (Figure 10). This means that the longer the enzymes are kept at room temperature, the more activity increase can be detected in the sample of amylase mixed with 


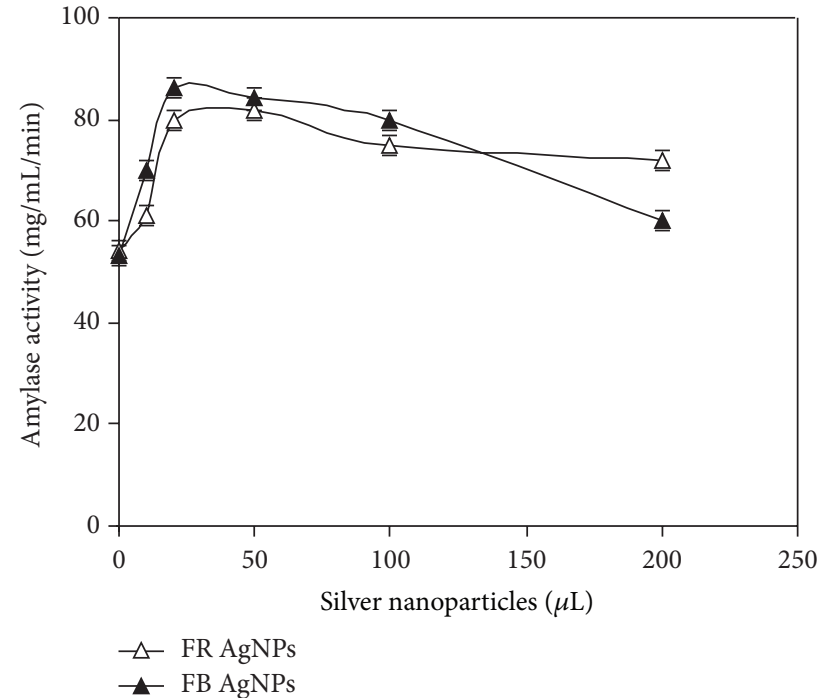

(a)

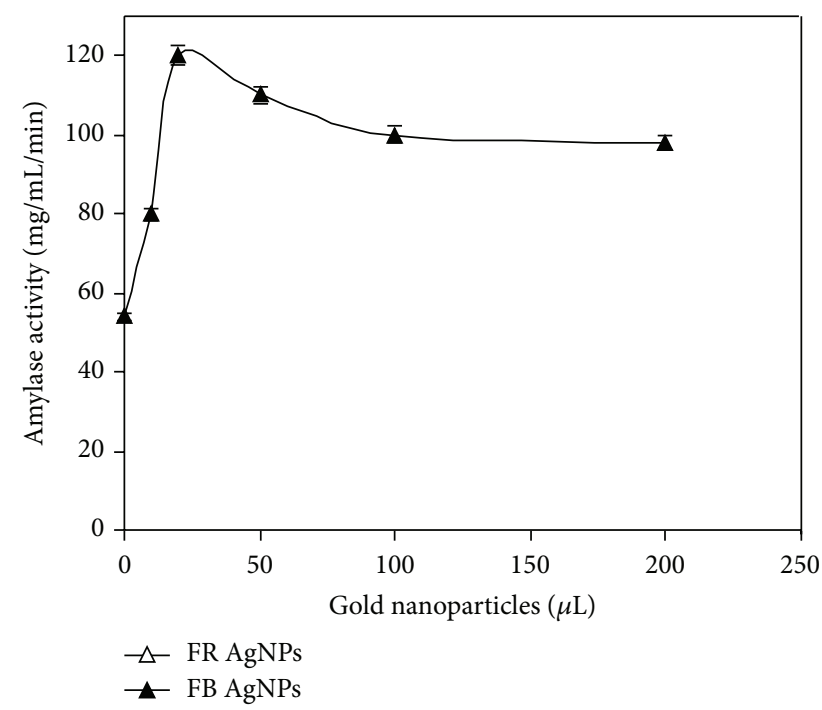

(b)

Figure 7: Modulatory effect of silver and gold nanoparticles on $\alpha$ amylase activity. (a) ( $\boldsymbol{\Delta})$ : effect of FB AgNPs on amylase; $(\triangle)$ : effect of FR AgNPs on amylase; (b) effect of gold nanoparticles. Data points represent the mean of at least three determinations.

AuNPs or AgNPs solutions. This result clearly demonstrated that the AuNPs or AgNPs can stabilize the activity of amylase, when compared with the free enzyme.

\section{Conclusion}

In summary, biosynthesized AgNPs and AuNPs showed an increased rate of reaction with $\alpha$-amylase. The degradation of starch digestion kinetics in the presence of AgNPs/AuNPs rapidly produced larger amounts of reducing sugars. This study showed that the nanoparticle may have a significant effect in the field of nanocatalysis, promising their potential use in industries for rapid degradation of the complex

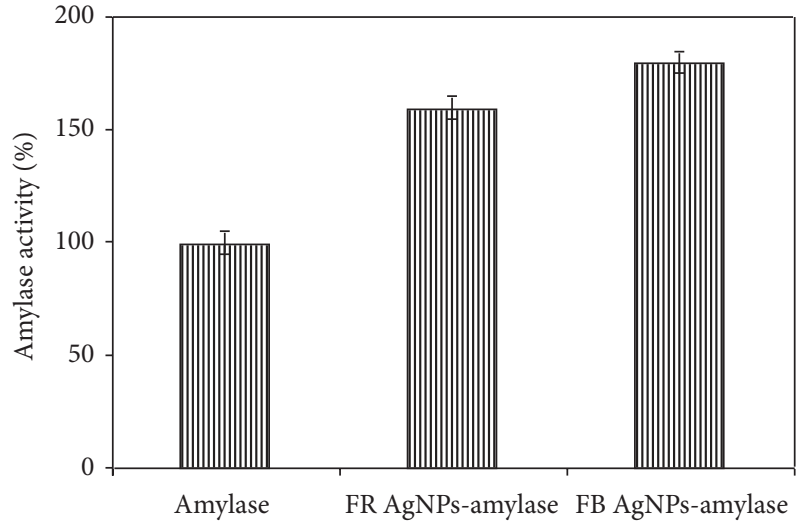

(a)

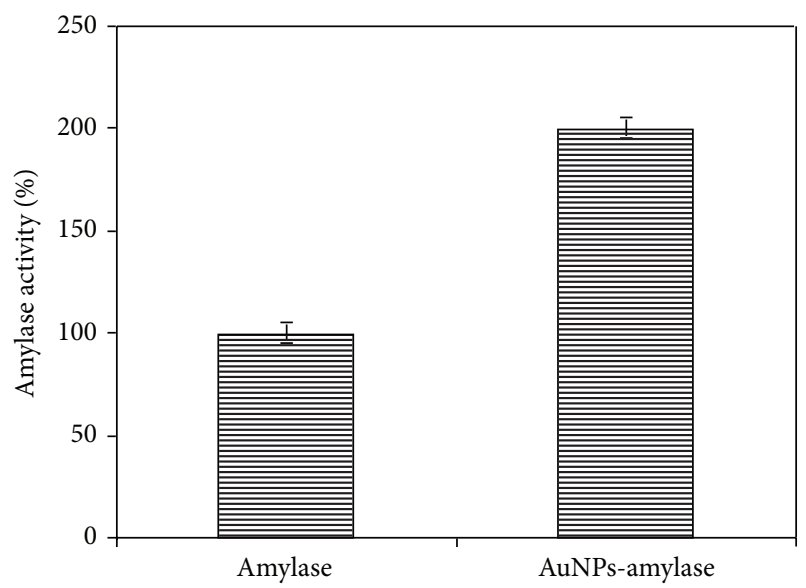

(b)

FIGURE 8: Assay of immobilized amylase activity. (a) Amylase + silver nanoparticles; (b) amylase + gold nanoparticles. Data points represent the mean of at least three determinations.

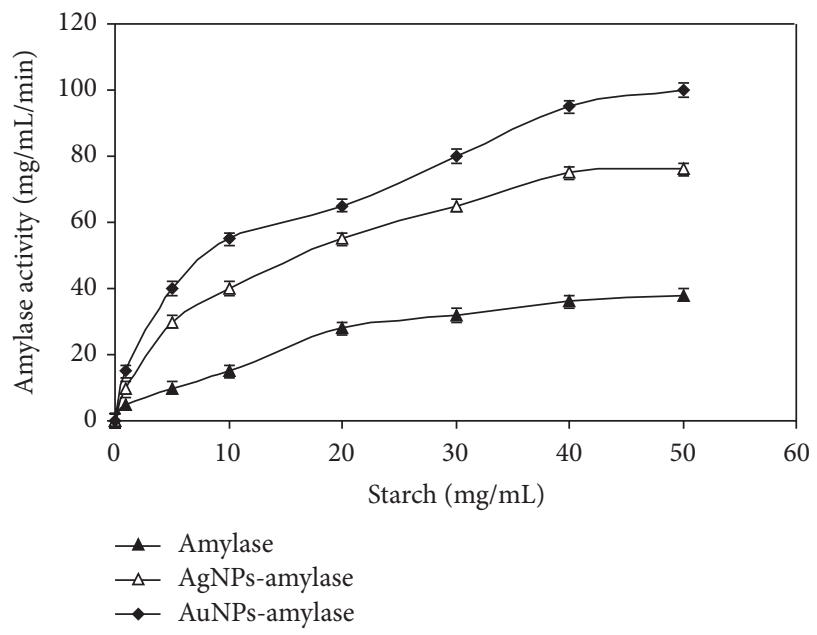

FIGURE 9: Effect of substrate concentrations on $\alpha$-amylase activity in the presence of nanoparticles as compared to the control (enzyme in absence of NPs). Legend represents the respective concentration of starch at which the experiments were carried out. The concentration of AgNPs/AuNPs was same for all of the above. Data points represent the mean of at least three determinations. 


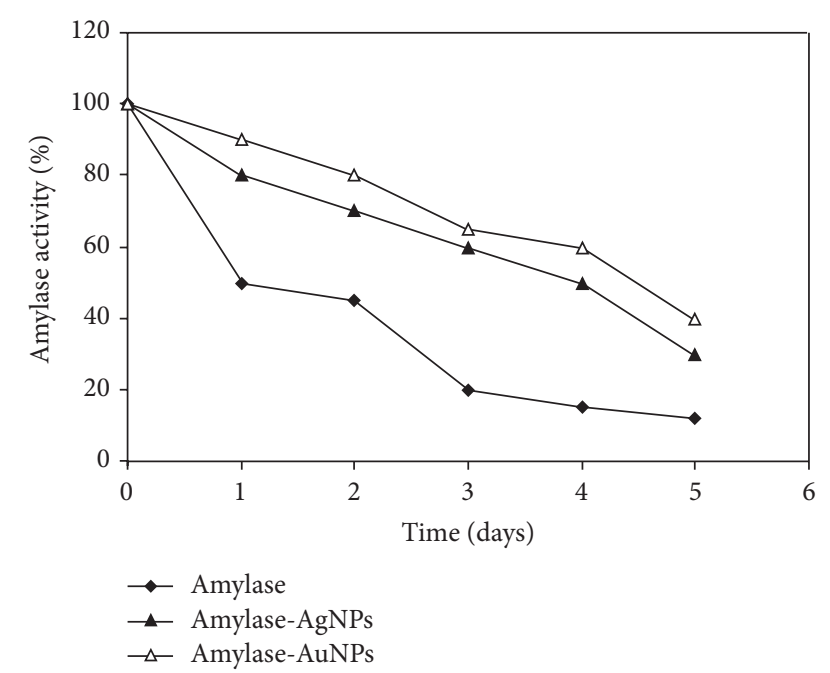

FIgURE 10: Comparison of storage stabilities of the free and immobilized $\alpha$-amylase at room temperature. Data points represent the mean of at least three determinations.

molecule to simpler ones by immobilizing the enzymes onto the surface of nanoparticles. They could also be possibly used in assay kits as they are less time consuming and for biomedical applications such as drug delivery and sensing.

\section{Conflict of Interests}

The authors report no conflict of interests. The authors alone are responsible for the content and writing of the paper.

\section{Authors' Contribution}

Kantrao Saware and Ravindra Mahadappa Aurade contributed equally to the paper.

\section{Acknowledgments}

The author Kantrao Saware thanks Professor G. U. Kulkarni for fruitful guidance and Selvi Rajan, JNCASR Bangalore, for FESEM measurements. Venkataraman Abbaraju thanks UGC, New Delhi, Government of India, for financial support in the form of project. Kantrao Saware thanks Dr. Shivashankar KS, IIHR, Bangalore, for providing fluorescence spectrophotometer.

\section{References}

[1] S. P. Gubin, Y. A. Koksharov, G. B. Khomutov, and G. Y. Yurkov, "Magnetic nanoparticles: preparation, structure and properties," Russian Chemical Reviews, vol. 74, no. 6, pp. 489520, 2005.

[2] K. J. Dussán, O. H. Giraldo, and C. A. Cardona, "Application of magnetic nanostructures in biotechnological processes: biodiesel production using lipase immobilized on magnetic carriers," in Proceedings of the European Congress of Chemical Engineering, Copenhagen, Denmark, September 2007.
[3] D. Roe, B. Karandikar, N. Bonn-Savage, B. Gibbins, and J.B. Roullet, "Antimicrobial surface functionalization of plastic catheters by silver nanoparticles," Journal of Antimicrobial Chemotherapy, vol. 61, no. 4, pp. 869-876, 2008.

[4] C.-F. Chau, S.-H. Wu, and G.-C. Yen, "The development of regulations for food nanotechnology," Trends in Food Science and Technology, vol. 18, no. 5, pp. 269-280, 2007.

[5] F. Furno, K. S. Morley, B. Wong et al., "Silver nanoparticles and polymeric medical devices: a new approach to prevention of infection?" Journal of Antimicrobial Chemotherapy, vol. 54, no. 6, pp. 1019-1024, 2004.

[6] M. Das, C. Mohanty, and S. K. Sahoo, "Ligand-based targeted therapy for cancer tissue," Expert Opinion on Drug Delivery, vol. 6, no. 3, pp. 285-304, 2009.

[7] X. Ren, X. Meng, D. Chen, F. Tang, and J. Jiao, "Using silver nanoparticle to enhance current response of biosensor," Biosensors and Bioelectronics, vol. 21, no. 3, pp. 433-437, 2005.

[8] V. Ernest, P. J. Shiny, A. Mukherjee, and N. Chandrasekaran, "Silver nanoparticles: a potential nanocatalyst for the rapid degradation of starch hydrolysis by $\alpha$-amylase," Carbohydrate Research, vol. 352, pp. 60-64, 2012.

[9] Z. Wang, R. Lévy, D. G. Fernig, and M. Brust, "Kinasecatalyzed modification of gold nanoparticles: a new approach to colorimetric kinase activity screening," Journal of the American Chemical Society, vol. 128, no. 7, pp. 2214-2215, 2006.

[10] M. R. Choi, K. J. Stanton-Maxey, J. K. Stanley et al., "A cellular trojan horse for delivery of therapeutic nanoparticles into tumors," Nano Letters, vol. 7, no. 12, pp. 3759-3765, 2007.

[11] R. Bonomi, A. Cazzolaro, A. Sansone, P. Scrimin, and L. J. Prins, "Detection of enzyme activity through catalytic signal amplification with functionalized gold nanoparticles," Angewandte Chemie: International Edition, vol. 50, no. 10, pp. 2307-2312, 2011.

[12] P. Pandey, S. P. Singh, S. K. Arya et al., "Application of thiolated gold nanoparticles for the enhancement of glucose oxidase activity," Langmuir, vol. 23, no. 6, pp. 3333-3337, 2007.

[13] K. G. Kouassi, J. Irudayaraj, and G. McCarthy, "Examination of cholesterol oxidase immobilization onto magnetic nanoparticles," BioMagnetic Research and Technology, vol. 3, article 1, 2005.

[14] B. J. Jordan, R. Hong, G. Han, S. Rana, and V. M. Rotello, "Modulation of enzyme-substrate selectivity using tetraethylene glycol functionalized gold nanoparticles," Nanotechnology, vol. 20, no. 43, Article ID 434004, 2009.

[15] G. K. Ahirwal and C. K. Mitra, "Direct electrochemistry of horseradish peroxidase-gold nanoparticles conjugate," Sensors, vol. 9, no. 2, pp. 881-894, 2009.

[16] L. M. Rossi, A. D. Quach, and Z. Rosenzweig, "Glucose oxidasemagnetite nanoparticle bioconjugate for glucose sensing," Analytical and Bioanalytical Chemistry, vol. 380, no. 4, pp. 606-613, 2004.

[17] M. M. Varma, D. D. Nolte, H. D. Inerowicz, and F. E. Regnier, "Spinning-disk self-referencing interferometry of antigen-antibody recognition," Optics Letters, vol. 29, no. 9, pp. 950-952, 2004.

[18] J.-M. Nam, C. S. Thaxton, and C. A. Mirkin, "Nanoparticlebased bio-bar codes for the ultrasensitive detection of proteins," Science, vol. 301, no. 5641, pp. 1884-1886, 2003.

[19] A. G. Tkachenko, H. Xie, Y. Liu et al., "Cellular trajectories of peptide-modified gold particle complexes: comparison of nuclear localization signals and peptide transduction domains," Bioconjugate Chemistry, vol. 15, no. 3, pp. 482-490, 2004. 
[20] L. R. Hirsch, R. J. Stafford, J. A. Bankson et al., "Nanoshellmediated near-infrared thermal therapy of tumors under magnetic resonance guidance," Proceedings of the National Academy of Sciences of the United States of America, vol. 100, no. 23, pp. 13549-13554, 2003.

[21] G. Scrinis and K. Lyons, "The emerging nano-corporate paradigm: nanotechnology and the transformation of nature, food and agri-food systems," International Journal of Sociology of Agriculture and Food, vol. 15, no. 2, pp. 22-44, 2007.

[22] I. Lynch and K. A. Dawson, "Protein-nanoparticle interactions," Nano Today, vol. 3, no. 1-2, pp. 40-47, 2008.

[23] I. Lynch, T. Cedervall, M. Lundqvist, C. Cabaleiro-Lago, S. Linse, and K. A. Dawson, "The nanoparticle-protein complex as a biological entity; a complex fluids and surface science challenge for the 21st century," Advances in Colloid and Interface Science, vol. 134-135, pp. 167-174, 2007.

[24] P. Ghosh, G. Han, M. De, C. K. Kim, and V. M. Rotello, "Gold nanoparticles in delivery applications," Advanced Drug Delivery Reviews, vol. 60, no. 11, pp. 1307-1315, 2008.

[25] A. E. Nel, L. Mädler, D. Velegol et al., "Understanding biophysicochemical interactions at the nano-bio interface," Nature Materials, vol. 8, no. 7, pp. 543-557, 2009.

[26] A. Lesniak, F. Fenaroli, M. P. Monopoli, C. Åberg, K. A. Dawson, and A. Salvati, "Effects of the presence or absence of a protein corona on silica nanoparticle uptake and impact on cells," ACS Nano, vol. 6, no. 7, pp. 5845-5857, 2012.

[27] L. Lartigue, C. Wilhelm, J. Servais et al., "Nanomagnetic sensing of blood plasma protein interactions with iron oxide nanoparticles: impact on macrophage uptake," ACS Nano, vol. 6, no. 3, pp. 2665-2678, 2012.

[28] A. Verma and V. M. Rotello, "Surface recognition of biomacromolecules using nanoparticle receptors," Chemical Communications, no. 3, pp. 303-312, 2005.

[29] C. M. McIntosh, E. A. Esposito III, A. K. Boal, J. M. Simard, C. T. Martin, and V. M. Rotello, "Inhibition of DNA transcription using cationic mixed monolayer protected gold clusters," Journal of the American Chemical Society, vol. 123, no. 31, pp. 7626-7629, 2001.

[30] M. Thomas and A. M. Klibanov, "Conjugation to gold nanoparticles enhances polyethylenimine's transfer of plasmid dna into mammalian cells," Proceedings of the National Academy of Sciences of the United States of America, vol. 100, no. 16, pp. 91389143, 2003.

[31] N. O. Fischer, A. Verma, C. M. Goodman, J. M. Simard, and V. M. Rotello, "Reversible "irreversible" inhibition of chymotrypsin using nanoparticle receptors," Journal of the American Chemical Society, vol. 125, no. 44, pp. 13387-13391, 2003.

[32] P. Kumari and P. Majewski, "Adsorption of albumin on silica surfaces modified by silver and copper nanoparticles," Journal of Nanomaterials, vol. 2013, Article ID 839016, 7 pages, 2013.

[33] S. P. Boulos, T. A. Davis, J. A. Yang et al., "Nanoparticleprotein interactions: a thermodynamic and kinetic study of the adsorption of bovine serum albumin to gold nanoparticle surfaces," Langmuir, vol. 29, no. 48, pp. 14984-14996, 2013.

[34] V. Banerjee and K. P. Das, "Interaction of silver nanoparticles with proteins: a characteristic protein concentration dependent profile of SPR signal," Colloids and Surfaces B: Biointerfaces, vol. 111, pp. 71-79, 2013.

[35] L. Shang, L. Yang, J. Seiter et al., "Nanoparticles interacting with proteins and cells: a systematic study of protein surface charge effects," Advanced Materials Interfaces, vol. 1, no. 2, Article ID 1300079, 2014.
[36] J. Turkevich, P. C. Stevenson, and J. Hillier, "A study of the nucleation and growth processes in the synthesis of colloidal gold," Discussions of the Faraday Society, vol. 11, pp. 55-75, 1951.

[37] P. V. Kamat, Nanoparticles and Nanostructured Films, John Wiley \& Sons, New York, NY, USA, 1998.

[38] K. Saware and A. Venkataraman, "Biosynthesis and characterization of stable silver nanoparticles using Ficus religiosa leaf extract: a mechanism perspective," Journal of Cluster Science, vol. 25, no. 4, pp. 1157-1171, 2014.

[39] R. Liu, A. Siemiarczuk, and F. J. Sharom, "Intrinsic fluorescence of the P-glycoprotein multidrug transporter: sensitivity of tryptophan residues to binding of drugs and nucleotides," Biochemistry, vol. 39, no. 48, pp. 14927-14938, 2000.

[40] S.-H. Huang, M.-H. Liao, and D.-H. Chen, "Direct binding and characterization of lipase onto magnetic nanoparticles," Biotechnology Progress, vol. 19, no. 3, pp. 1095-1100, 2003.

[41] J. Deka, A. Paul, and A. Chattopadhyay, "Modulating enzymatic activity in the presence of gold nanoparticles," RSC Advances, vol. 2, no. 11, pp. 4736-4745, 2012.

[42] A. Rangnekar, T. K. Sarma, A. K. Singh, J. Deka, A. Ramesh, and A. Chattopadhyay, "Retention of enzymatic activity of $\alpha$-amylase in the reductive synthesis of gold nanoparticles," Langmuir, vol. 23, no. 10, pp. 5700-5706, 2007.

[43] D. Raghunandan, M. D. Bedre, S. Basavaraja, B. Sawle, S. Y. Manjunath, and A. Venkataraman, "Rapid biosynthesis of irregular shaped gold nanoparticles from macerated aqueous extracellular dried clove buds (Syzygium aromaticum) solution," Colloids and Surfaces B: Biointerfaces, vol. 79, no. 1, pp. 235-240, 2010.

[44] X. P. Zhu, T. Suzuki, T. Nakayama, H. Suematsu, W. Jiang, and K. Niihara, "Underwater laser ablation approach to fabricating monodisperse metallic nanoparticles," Chemical Physics Letters, vol. 427, no. 1-3, pp. 127-131, 2006.

[45] N. V. Tarasenko, A. V. Butsen, E. A. Nevar, and N. A. Savastenko, "Synthesis of nanosized particles during laser ablation of gold in water," Applied Surface Science, vol. 252, no. 13, pp. 4439-4444, 2006.

[46] F. Mafuné, J.-Y. Kohno, Y. Takeda, and T. Kondow, "Full physical preparation of size-selected gold nanoparticles in solution: laser ablation and laser-induced size control," Journal of Physical Chemistry B, vol. 106, no. 31, pp. 7575-7577, 2002.

[47] S. A. R. Abbas, "The effects of gold and silver nanoparticles on choline estrase and Monoamino oxidase enzymes activities," International Journal of Chemistry, vol. 3, no. 4, pp. 61-68, 2011.

[48] J. Deka, A. Paul, A. Ramesh, and A. Chattopadhyay, "Probing Au nanoparticle uptake by enzyme following the digestion of a starch-Au-nanoparticle composite," Langmuir, vol. 24, no. 18, pp. 9945-9951, 2008.

[49] X. Jiang, J. Jiang, Y. Jin, E. Wang, and S. Dong, "Effect of colloidal gold size on the conformational changes of adsorbed cytochrome $c$ : probing by circular dichroism, UV-visible, and infrared spectroscopy," Biomacromolecules, vol. 6, no. 1, pp. 4653, 2005.

[50] A. Gole, C. Dash, C. Soman, S. R. Sainkar, M. Rao, and M. Sastry, "On the preparation, characterization, and enzymatic activity of fungal protease-gold colloid bioconjugates," Bioconjugate Chemistry, vol. 12, no. 5, pp. 684-690, 2001. 

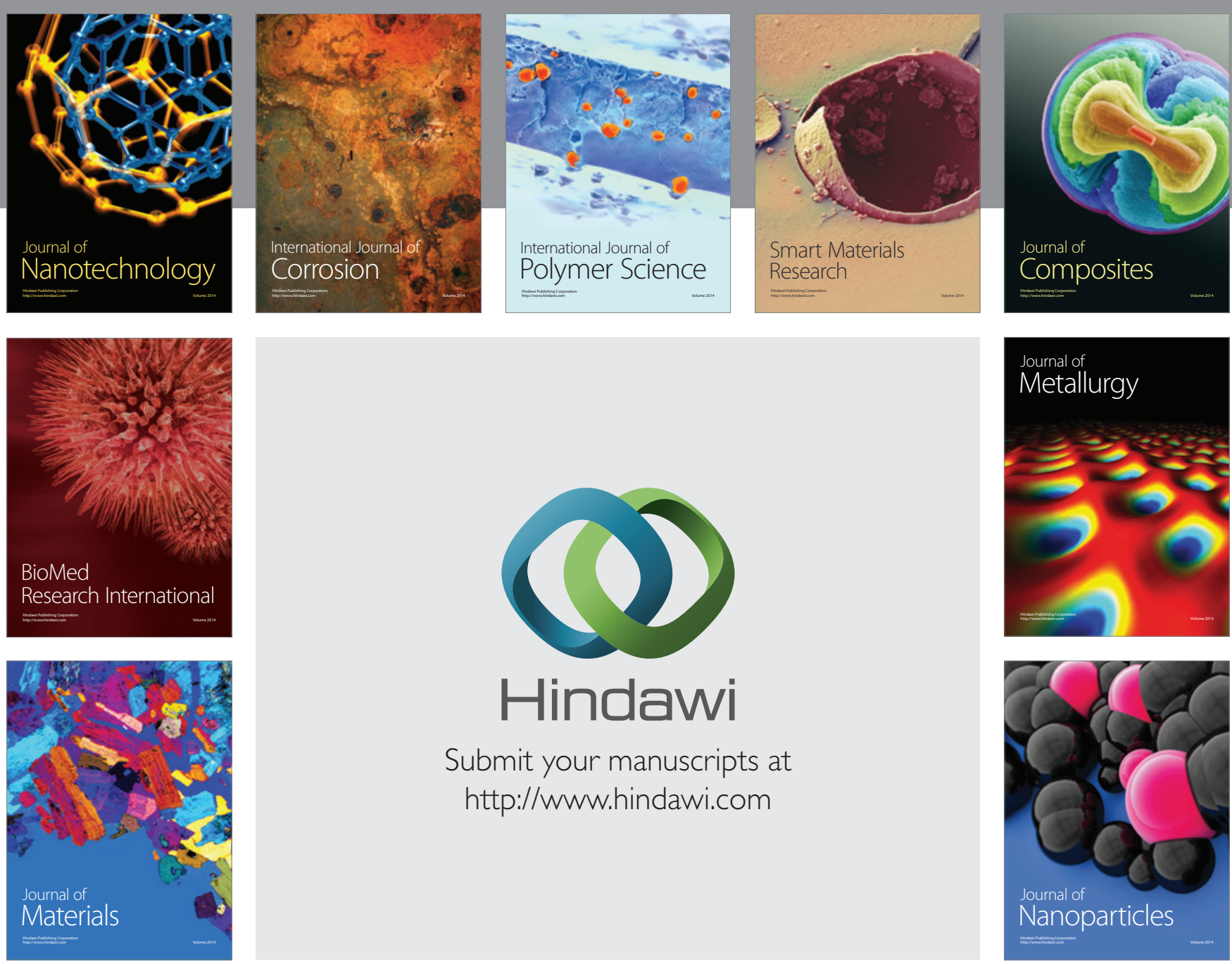

Submit your manuscripts at http://www.hindawi.com
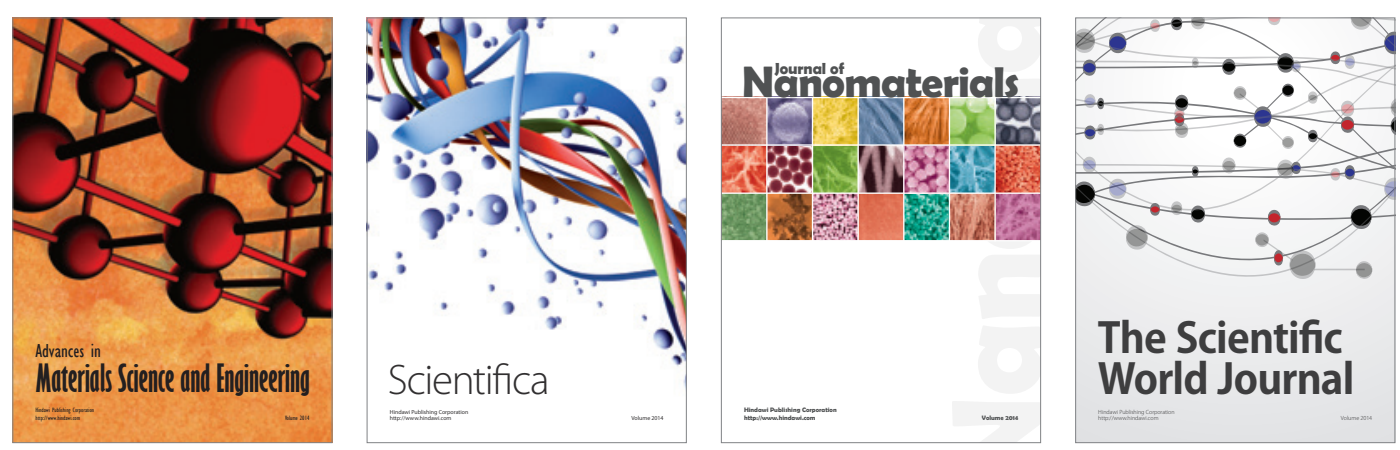

\section{The Scientific World Journal}
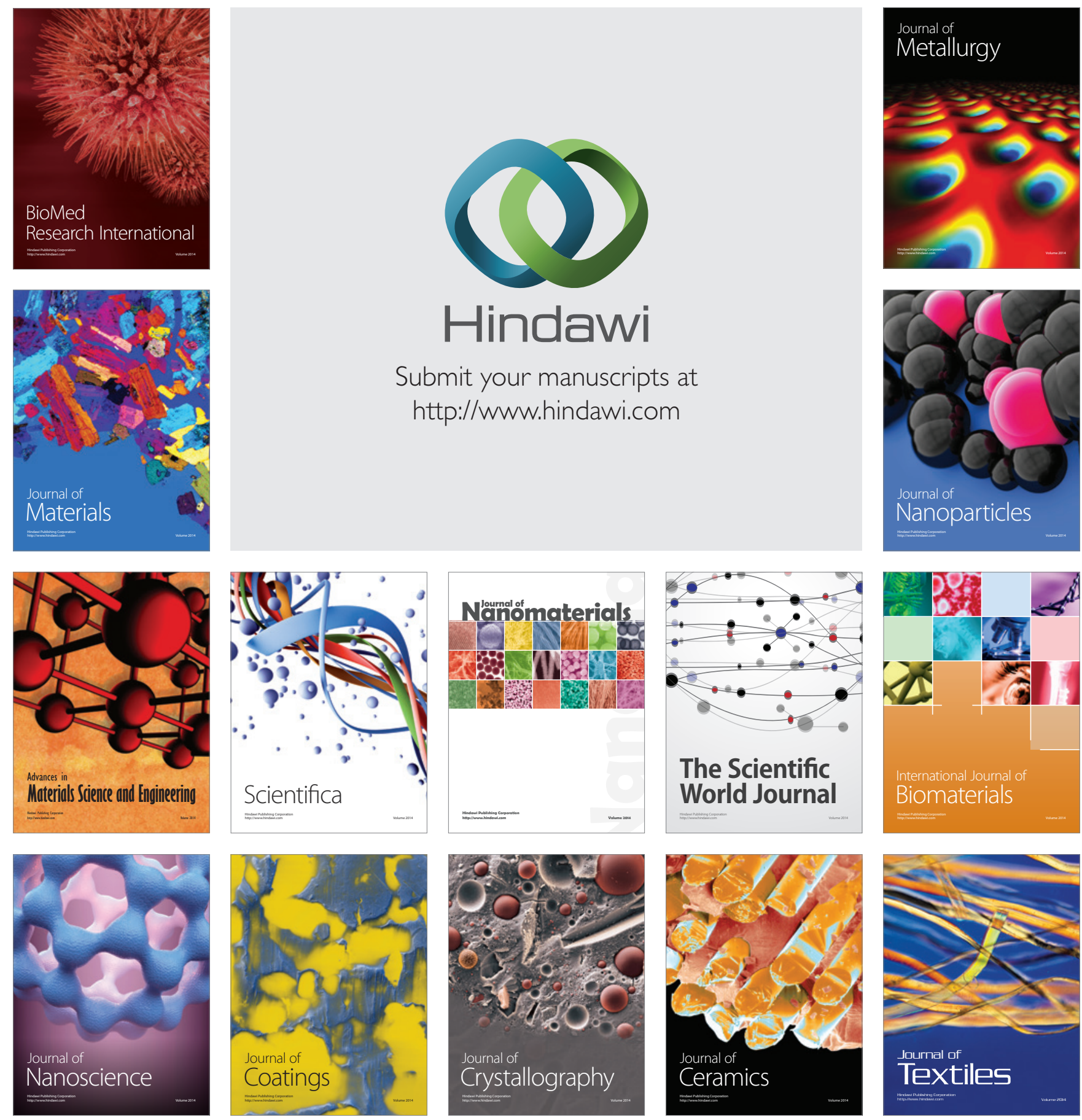